\title{
The Assessment of the Translation of Chang Hen $G e$ on the Basis of Textuality
}

\author{
Yanping Zheng \\ College of Foreign Languages, North China Institute of Science and Technology, China \\ Email: pyzhengaas@163.com \\ Xuemei Cheng \\ The Library of North China Institute of Science and Technology, China \\ Email: yanping@ncist.edu.cn
}

\begin{abstract}
This paper expounds the definition of a text and points out that translation is text oriented. Then it elaborates on the standards of textuality and it attaches importance to the application of textuality to the assessment of the translations of Chang Hen Ge. It can be seen that translation assessment made on the basis of textuality is more operational in translation practice.
\end{abstract}

Index Terms - text, textuality translation, assessment

As we know, the objects of translation are texts, the process of translating starts from a given text, the translator analyzes the text, and the final product of the process is a new text in the target language. And the analysis of texts is indispensable if a translation product is to be assessed.

\section{What IS A TeXt?}

There might be diverse answers to this question.

A text, which a discourse consists of, is "a complete utterance", it is "anything from an isolated Ouch! to an entire poem, essay, conversation, lecture, or book"(Nida,1998,p.78). Here Nida equates text with discourse. Maybe this definition covers too much and it is beyond the limit of a text for it is more suitable for discourse.

A text is a semantic unit with its function and meaning and it is a process and product of man's communication under certain context (Chen, 1998) This definition is raised in terms of semantics. It tells us one of the main features of a text, that is, the semantic element of a text. But a sentence, the minimum part of language that expresses a complete thought (Hu, 1989), is also possible to be a semantic unit with certain function and meaning. As a result, confusion of these two is likely to be caused due to the overlapping part of a sentence and a text.

And still there is another definition according to Brown and Yule (1987, p.190) which says: "Text, we said, is the verbal record of a communicative event." Here text is defined in connection with communication, that is, pragmatics (the study of language in use and linguistic communication) is involved. This involvement exposes another important feature of a text to us, the pragmatic element of a text. But a text possesses something more.

And another definition which is impossible to be ignored is presented by Halliday and Hasan (1976, p.2) who take the view that "A text is best regarded as a semantic unit: a unit not of form but of meaning" and the primary determinant of whether a set of sentences do or do not constitute a text depends on cohesive relationship within and between the sentences, which creates texture. "A text has texture and this is what distinguishes it from something that is not a text. The texture is provided by the cohesive RELATION".

This definition also mentions another significant and distinctive feature of a text, that is, the "cohesive relationship within and between the sentences" of a text. Yet it is not sufficient to be used as a standard to justify a text because some sentences are cohesive in a passage, however, they can't form a good text.

According to Werlich (1976), a text is characterized by coherence and completion. He (2002) attaches great importance to the logicality of a text when analyzing text and maintains that logicality is the essence of the constitution of a text and the key to comprehend a text.

Beaugrande and Dressler (2002) hold the view that a text is a communicative occurrence which meets seven standards of textuality: cohesion, coherence, intentionality, acceptability, informativity, situationality and intertextuality. If any of these standards is not considered to have been satisfied, the text will not be communicative. Hence, non-communicative texts are treated as non-texts.

From the above discussion, some common important characteristics concerning a text can be attained. First, a text is communicative. Second, a text possesses textuality (or texture), a distinctive feature separating a text from a non-text. And third, the language form of a text can be either spoken or written. Thus, the definition presented by Beaugrande and Dressler will be adopted in this thesis for the reason that it reveals the function of a text and the essence of a text, i.e. textuality which plays a significant role in text analysis and in translation. 


\section{The SEVEn Standards OF TeXtuality And Translation Assessment}

Beaugrande and Dressler (2002) hold the view that for a 'linguistics of the text', at least three perspectives seemed vitally relevant: (a) the text itself as process and product with mainly 'linguistic' qualities; (b) the participants, usually the producer(s) and the receiver(s) of the text; and (c) the broader context of situation wherein the text and the participants are situated. To address these three perspectives, they came to recognize seven standards of textuality. For the text itself, cohesion subsumes the means for connecting units and patterns, e.g., by joining two sentences through pronominalisation from noun phrase ('old woman') to pronoun ('She') in sample; and coherence subsumes the means for connecting meanings and concepts, e.g., by describing 'eyes' and 'mouth' to portray 'ugliness'. For the participants, intentionality designates the condition that the text producer intends to perform an event as a text, e.g., to bewail the 'hardness' of one's own 'daughter'; and acceptability designates the condition that the text receiver accepts the event as a text, e.g., by confirming that same 'hardness' and making her 'dear mother' responsible. For the context of situation, informativity concerns the degrees to which the text or some of its aspects are unexpected, interesting, or stimulating, e.g., total amazement to see one's 'daughter' 'living and come back'; situationality concerns the connections between the text and the context of situation, e.g., a dramatic reunion where the mother melts with emotion and the daughter does not; and intertextuality concerns the connections between the current text and previously experienced texts, e.g., when the daughter picks up and expands the Topic of being 'hardened'.

These seven standards have been widely accepted, probably due to their practical usefulness in systematically exploring a text from multiple angles. They are not 'theoretical' in the sense of conventional 'linguistic theory' with its emphasis on entities like 'distinctive features' or 'deep structure'. Rather, they are intended to represent the practice-driven theories discourse participants sustain about texts, similar to the viewpoint of 'ethnomethodology'

Since the seven standards are for describing texts, and they can also be regarded as design criteria for evaluating texts. It is noticed that each of these may serve: how far the text is efficient in getting readily produced and received, effective in promoting intentions and goals, and appropriate to the context, the participants, and the situation, and the information as well.

And because of the fact that linguistic communication always appears in textual form, and modern linguistics is agreed upon the fact that the texts are primary form of linguistic manifestations. Texts show different conditions or origin, different structures, functions and they are designed for different recipients or target groups. They are produced for a large spectrum of communicative purposes. Translation, therefore, is a text-oriented event. The translator does not translate words or individual sentences (unless an isolated sentence has text status), but texts (Wilss, 2001). Consequently, to produce an equivalent target language text of a source language text means to render the message of the source language text on the basis of the textuality of a source language text. And more importantly, the seven standards can also be applicable when a translation is assessed which will be elaborated in the following part.

\section{The Assessment of the Translation of Chang Hen Ge (《长恨歌》) On the BASIS Of TeXtuality}

Chang Hen Ge, composed in 806 A.D. by Bai Juyi, an outstanding poet in ancient China, who lived during 772 and 846 in the middle years of the Tang Dynasty, is a famous poem vividly depicting the tragic love story between Emperor Xuanzong of the Tang Dynasty and his favorite imperial concubine Yang Yuhuan. The poet created an enthralling and moving story out of the historical figures and legends and represented the reality of life through the artistic images, which has touched numerous readers through the centuries. The outstanding feature of Chang Hen Ge in its artistic presentation is enhanced emotions, which are expressed from the satire on "The beauty-loving emperor, longed year after year, to find a great beauty without peer" to the sentiment and sympathy on "this eternal sorrow goes on and on for ever".

The Chinese poem comprises one hundred and twenty sentences (see Feng Qinghua, 2004, p.428-430). The translators Professor Xu Yuanchong (许泮冲) and Gladys Yang (杨宪益、戴乃迭) (From Feng Qinghua, 2004, p.430-440 for their translations) translated the poem in the form of poem, but they did it differently.

\section{A. The Assessment of the Translations in Terms of Intentionality}

Intentionality is concerned with the text producer's attitude that the set of occurrences should constitute a cohesive and coherent text instrumental in fulfilling the producer's intentions, e.g. to distribute knowledge or to attain a goal specified in a plan, designates all the ways in which text producers utilize texts to pursue and fulfill their intentions in a wider sense.

Consequently, when a translation is assessed, one should consider whether the intention of the source text producer is manifested in the target text, just as the fact that a translator should take into consideration the text producer's attitude or intentions and make the greatest efforts to fulfill the producer's intentions so as to achieve a faithful target text.

It can be noted that the rough intention of author Bai Juyi of Chang Hen Ge is to use the literary form of poem (the popular form of his time) to reveal the regretful love between Emperor Xuan Zong and Yang Yuhuan, and to satirize and criticize Emperor Xuan Zong's indulgence in beauty and his negligence of management of his state. The two versions by $\mathrm{Xu}$ Yuanchong and Gladys Yang retain the literary form of the source text and the intention of source text, although Xu Yuanchong's version is in better harmony with the source text in terms of structure, stanza and rhyme. 
So it can be stated that the two versions are qualified in terms of intentionality.

\section{B. The Assessment of the Translations in Terms of Cohesion}

Cohesion is a formal principle used in the assessment of a translation. A target text should be cohesive in form so as to make text easy for the receivers/recipients to follow and lay a foundation for the coherence of the text.

Cohesive ways include reference, ellipsis, substitution, conjunction, lexical cohesion and certain punctuation marks which may be applied, either retain those of the source text or make additions according to the requirements of the formation of the target text, as the basis and guidance for translation.

And it is evident that reference, ellipsis, conjunction, lexical cohesion are mainly employed in the two versions by the translators.

Reference refers to forms which "instead of being interpreted semantically in their own right...make reference to something else for their interpretation."(Halliday, 1976, p.31) Personal pronouns, demonstrative pronouns and words used to express comparison can play the role of reference. In the versions personal pronouns "he" and "she" are most frequently used. "They" and "it" are also used several times. These words are added mainly in the target text to be the subjects of sentences for the fact that there exist no such pronouns in the source text but they have to appear in the sentences of the target text resulting from the difference in the formation of sentences in Chinese and English. And mostly the use of such personal pronouns in the two versions is proper except for one contradiction in Gladys Yang's version in the following lines:

134. A priest from Linqiong came to Chang'an,

137. He sent a magician to make a careful search.

140. Though they searched the sky and nether regions,

142. Till he heard of a fairy mountain

149. When he knocked at the jade door

Here if "they" is changed by "he", it would be more reasonable.

The use of ellipsis in the two versions is rare. When translating the stanza “在天愿作比翼鸟，在地愿为连理枝。”, both of the two groups of translators use ellipsis as in the following:

"In heaven we shall be birds

Flying side by side.

On earth flowering sprigs

On the same branch!"

Translated by Gladys Yang

"On high, we'd be two lovebirds flying wing to wing;

On earth, two trees with branches twined from spring to spring."

Translated by Xu Yuanchong

It is obvious that in the versions "we shall be" and "we'd be" are omitted because of the parallel structure of the source text sentences. And such use is completely acceptable.

As to the use of conjunctions, it is calculated that in Gladys Yang's version, 31 conjunctions have been used. The proportion of conjunctions in the target text to the sentences in the source text is $25.8 \%$. And 22 conjunctions are utilized in Xu Yuanchong's version. The proportion is $18.3 \%$. It can be said that Gladys Yang's version is more explicit for target readers for its more use of conjunctions. And the use of conjunctions in the two versions undoubtedly enhances the coherence of the target text.

With regard to the use of lexical cohesion, which refers to the conveying of cohesive relationship by means of repetition, synonyms, antonyms, collocations and others, it can be noticed that repetition and synonyms are used in the two versions concerning Emperor Xuanzong of the Tang Dynasty and his favorite imperial concubine Yang Yuhuan, the two main characters in the poem. In Gladys Yang's version, such expressions as "The Han emperor", "the emperor", "Emperor" and "he" are used repeatedly or interchangeably to refer to Emperor Xuanzong. And his favorite imperial concubine Yang Yuhuan is referred to as "a daughter of the Yang family", "Taizhen", "his first lady" and "she". While in $\mathrm{Xu}$ Yuanchong's version, Emperor Xuanzong is called "The beauty-loving monarch", "the monarch", "The Emperor", "the broken hearted", "her lord", and "he", and Yang Yuhuan "A maiden of the Yangs", "the Lady Yang","The fair-faced Lady Yang", "a queen", "Ever True", "the queen" and "she".

Such expressions are generally acceptable except for two of them. One is the use of "The Han emperor" for Emperor Xuanzong, the other is the use of "queen" in referring to Yang Yuhuan. The first use may cause misunderstanding among English readers, and the second use is not accurate for the fact that Yang Yuhuan is not a queen. So it is advisable that these two expressions be replaced by other proper ones.

\section{The Assessment of the Translations in Terms of Coherence}

To make communication efficient, a text as a whole should be endowed with coherence. Baker (1992) holds the view that coherence is the network of conceptual relations which underlie the surface text.

The two versions are coherent respectively as target texts for both of them communicate the happy and regretful love story between Emperor Xuanzong of the Tang Dynasty and his favorite imperial concubine Yang Yuhuan. Yet if the 
two versions are studied thoroughly in terms of explanatory coherence, which not only establishes continuity of senses but also justifies it (Baker, 1992), one may discover certain lines which are not coherent.

For instance, in Xu Yuanchong's version, there are such lines as in the following:

" 57 . Back, he found her pond and garden in the old place,

58.With lotus in the lake and willows by the hall."

“(57)归来池苑皆依旧，(58)太液芙蓉未央柳。”

“77. Moved by the monarch's yearning for the departed fair,

78. He was ordered to seek for her everywhere."

“(77)为感君王辗转思, (78)遂教方士殷勤受。”

and "86. And dwelt so many fairies as graceful as flowers.

87. Among them was a queen whose name was Ever True;"

“(86)其中绰约多仙子。(87)中有一人字太真, ”

It is apparent that there is no continuity of senses within every two lines in the above. That means these lines are not coherent completely. So there is some room for improvement in translating these lines.

\section{The Assessment of the Translations in Terms of Acceptability}

Acceptability emphasizes on the text receiver's attitude that the set of occurrences should constitute a cohesive and coherent text having some use or relevance for the receiver, e.g. to acquire knowledge or provide co-operation in a plan (Beaugrande and Dressler, 2002).

It can be safely said that the two versions are acceptable for their fulfillment of intention of the text producer and the translators' Skopos, and the versions are cohesive and coherent wholly.

It seems that, as is mentioned above, there is still some room for improvement. If "The Han emperor" in Gladly Yang's version and "The beauty-loving monarch" in Xu Yuanchong's version are converted to Emperor Xuanzong, the use of "queen" in Xu Yuanchong's version to Yang Yuhuan, and the incoherent lines above are modified, both of the two versions may become more accurate and more acceptable.

\section{E. The Assessment of the Translations in Terms of Informativity}

As is mentioned in third part informativity is used to designate the extent to which a presentation is new or unexpected for the receivers. Beaugrande and Dressler (2002) have proposed a range of three orders of informativity, each sufficiently broad that human language users might be able to distinguish them during actual communication.

The occurrence of an option in the upper range of probability, i.e., perceptibly among the most likely candidates, would convey first-order informativity. First-order occurrences are rather trivial, that is, so well integrated into a system or setting that they receive very slight attention. First-order informativity would always be present in any text, whether or not higher orders are attained.

When translating a text, a translator can make the target text vary within the range of three orders of informativity in the light of text producer's intentions and the acceptability from the perspective of text receivers besides keeping the order of information of the source text. And a translator should also take into consideration the client's requirement or the Skopos of doing the task. These are the premises that a text is translated and assessed as well.

On the basis of this, the two versions have attained the goal of informativity, that is, they have provided the first-order occurrences of the source text. Of course, Xu Yuanchong's version is of higher order of informativity for its low frequency in use of conjunctions.

\section{F. The Assessment of the Translations in Terms of Situationality}

It is mentioned that the term situationality, is a general designation for the factors which render a text relevant to a current or recoverable situation of occurrence. And the key point is that whether a text is acceptable may depend not on the "correctness" of its "reference" to the "real world," but rather on its believability and relevance to the participants" outlook regarding the situation.

And it has been pointed out that a translator can put the idea into his/her translation practice, that is, to do translation by analyzing situations contained in the source text and reconstruct such situations in the target text. Therefore, when assessing a translation, one may focus on whether the situations are reconstructed successfully.

As to the translation of Chang Hen Ge, it is quite clear that there are four key situations in the long poem. The first situation (from sentence No.1 to No.30) describes Yang Yuhuan's being chosen by Emperor Xuanzong of the Tang Dynasty and his excessive love for her. The second situation (from sentence No.31 to No.50) covers Yang Yuhuan's death because of a revolt and the emperor's sorrow. The third situation (from sentence No.51 to No.74) depicts the Emperor's great miss of her. The last situation (from sentence No.75 to No.120) focuses on Yang Yuhuan's love for the Emperor in another world.

The translators of the two versions translated the poem line after line in accordance with the source text. And the four situations of the source text have been reconstructed in the target versions. In this sense, the two versions are successful translation product by the translators.

\section{G. The Assessment of the Translations in Terms of Intertextuality}


It is mentioned that every text is constructed as a mosaic of citations, every text is an absorption and transformation of other texts. Intertextuality is concerned with the ways in which the production and reception of a given text depend upon the participants' knowledge of other texts. This knowledge can be applied by a process describable in terms of mediation. It is indispensable for a translator to perform translation under the guidance of the theory of intertextuality, that is, to produce a successful target text on the basis of the translator's knowledge of the two categories of inter-textual referential system of other relevant texts.

Thus, when assessing a translation product, one should apply the theory of intertextuality.

When assessed in terms of intertextuality, the two versions are undoubtedly good poems. And some difference between versions lies in that Xu Yuanchong's version is in better harmony with the source text in terms of structure, stanza and rhyme. And Gladys Yang's version does not have strict rhyme in every stanza in comparison to the source text, but there is a balance in terms of cadence within every stanza.

\section{CONCLUSION}

From the discussion above, it can be seen that the seven standards of textuality can not only be employed to distinguish texts from non-texts, but more importantly they are applicable in the assessment of translation products as well. To be exact, a translation product can be assessed in terms of cohesion, coherence, intentionality, acceptability, informativity, situationality and intertextuality, which makes translation assessment more operational in translation practice.

\section{REFERENCES}

[1] Baker, M.(1992). In Other Words: A Course-book on Translation. London: Routledge.

[2] Beaugrande R. De \& W. Dressler. (2002). Introduction to Text Linguistics (Digitally reformatted). London: Longman.

[3] Brown, Gillian \& Yule, George. (1987). Discourse Analysis. Avon: The Bath Press.

[4] Chen Hongwei. (1998). Essential Translation From Chinese to English. Shanghai: Shanghai Foreign Language Education Press.

[5] Feng Qinghua. (2004). A Practical Coursebook on Translation. Shanghai: Shanghai Foreign Language Education Press.

[6] Halliday, M. \& Hasan, R. (1976). Cohesion in English. London: Longman.

[7] He Shanfen. (2002). Contrastive Studies of English and Chinese Languages. Shanghai: Shanghai Foreign Language Education Press.

[8] Hu Zhuanglin \& Liu Runqing. (1989). Linguistics: A Course Book. Beijing: Beijing University Press.

[9] Nida, E.A. (1998). Language Culture and translation. Shanghai: Shanghai Foreign Language Education Press.

[10] Werlich, E. (1976). A Text Grammar of English. Heidelberg: Wuelle \& Meyer. (Chap. 2).

[11] Wilss, Wolfram. (2001). The Science of Translation Problems and Methods. Shanghai: Shanghai Foreign Language Education Press.

Yanping Zheng was born in Jingmen, Hubei province, China in 1969. He received his Ph.D. degree in translation studies from Shanghai International Studies University.

He is currently a professor in College of Foreign Languages of North China Institute of Science and Technology, East of Beijing, China. His research interests include translation studies and second language acquisition.

Xuemei Cheng was born in Jingmen, Hubei province, China in 1972. She received her bachelor's degree in information technology from Hebei University of Engineering.

She is currently a librarian in the library of North China Institute of Science and Technology. Her research interests include information management and accounting. 